\title{
Labelling of fluoridated toothpaste in South Africa
}

SADJ March 2019, Vol. 74 No. 2 p74 - p81

LR Vorster ${ }^{1}$, S Naidoo ${ }^{2}$

\section{SUMMARY}

\section{Introduction}

Product labelling is essential for education and protection of consumers and is fundamental to product quality.

\section{Aim}

To evaluate the labelling of commercially available fluoridated toothpastes in South Africa (SA). To determine compliance with the South African National Standard (SANS).

\section{Design \& methods:}

A national, cross-sectional survey of 300 fluoridated toothpastes (12 brands, nine paediatric and 29 adult toothpaste types). Labels were appraised relative to a key identifier, product descriptor, country of production or distributor address, content description, batch identification, and expiry date.

\section{Results}

None demonstrated full compliance with SANS 1302:2008 (edition 1.1). Nearly three quarters of the labels ( $n=38 ; 71.05 \%)$ adhered to five of the six marking requirements, while the least compliant provided only product name and distributor address, neither of which has any bearing on consumer education, health benefits or product safety. SANS 1302:2008 omits labelling requirements considered mandatory by the ISO11609:2010 guideline in terms of consumer protection, but all the toothpastes displayed partial compliance with these omitted variables.

\section{Conclusion}

The quality of information provided is satisfactory due to partial compliance with the internationally accepted ISO11609:2010 framework, but there is a need for more stringent regulation and the ISO 11609:2010 framework should be adopted within SA.

\section{Keywords}

Labelling, standards, compliance.

\section{Author affiliations:}

1. Lesley Ross Vorster: BSc., BOH, MSc, Department of Community Oral Health, Faculty of Dentistry, University of the Western Cape, South Africa.

2. Sudeshni Naidoo: $P h D$, Emeritus Professor, Department of Community Oral Health, Faculty of Dentistry, University of the Western Cape, South Africa.

Corresponding author: Lesley Ross Vorster

11 Royland Crescent, Hout Bay 7806, South Africa.

Email: ry.lesley@gmail.com Cell: +27 (0)76 2795530

Author contributions:

1. Lesley Ross Vorster: Principal Researcher - $60 \%$

2. Sudeshni Naidoo: Co-author and Advisor - $40 \%$

\section{ACRONYMS \\ CTFA: Cosmetics, Toiletries and Fragrance Association of South Africa \\ FDA: $\quad$ Federal Drug Administration \\ ISO: International Organisation for Standardisation (International Standards Organisation) \\ SANS: $\quad$ South African National Standards}

\section{BACKGROUND AND INTRODUCTION}

It is generally accepted that the preventive-therapeutic efficacy of the fluoridated toothpastes are reliant on the fluoride content. Systematic reviews of the literature have concluded that a minimum concentration of fluoride of 1000ppm be present in the formulation if caries is to be inhibited. ${ }^{1,2}$ Moreover, this fluoride needs to be chemically soluble in the formulation. ${ }^{3}$

Other factors relevant to toothpaste quality include the packaging and the marking practices. Packaging is fundamental in protecting the product against contamination from micro-organisms, moisture and dehydration while appropriate labelling that does not confuse or mislead by implication, provides a platform for effective communication with and education of, the consumer.

The major objective of the present study was to analyse labelling practices in terms of the information provided by the label and to assess the degree of conformity with prescribed marking regulations as stipulated by guidelines of the South African National Standards (SANS 1302:2008) and the International Organisation for Standardisation (ISO 11609:2010).

These documents were used as the benchmark for comparison even though their listed standards are not law and their application not mandatory. The recommended regulations are definitive for what may be regarded as acceptable and to which, at a minimum, manufacturers should adhere.

\section{South African National Standard}

- Toothpaste (1302:2008; ed. 1.1)

The SANS 1302:2008 (edition 1.1) guidelines pertaining to toothpastes was ratified by the National Committee of the South African Bureau of Standards SC271B, Cosmetics - Toothpastes, and was published in June 2008, superseding SANS 1302:1980 (edition 1). According to this standard, toothpaste is to be packaged in leak-proof, collapsible tubes bearing the total nominal volume or in the case of composite packs (i.e. two or more toothpastes of 
equivalent or differing net volume(s) and in which the tubes are separated from one another) the total nominal volume of the pack. Permissible volumes include $15 \mathrm{ml}, 35 \mathrm{ml}, 50 \mathrm{ml}, 75 \mathrm{ml}, 100 \mathrm{ml}, 125 \mathrm{ml}, 150 \mathrm{ml}$, $175 \mathrm{ml}$ and $200 \mathrm{ml}$.

Additionally, individual and composite packs are to be packaged in such a manner that affords protection against contamination and damage during transportation, handling and storage.

In terms of tube labelling, apart from nominal volume, the name of the toothpaste, the name and contact details of the manufacturer or responsible distributor, a description of content, batch number and, if the product is fluoridated, the phrase, "Fluoride Toothpaste" or "Fluoride Dental Crème" is to be displayed. This phrase is to be marked in a durable and intelligible manner with a font size of $3 \mathrm{~mm}$ and must be readily visible against the background. Similarly all marking requirements, excluding batch identification, as stipulated for the tube are to be applied in the labelling of the outer carton, packaging of composite packs and bulk packages.

International Organisation for Standardisation - ISO 11609:2010 Dentifrices ${ }^{5}$

In addition to all packaging and labelling norms prescribed in SANS 1302:2008, the International Organisation for Standardisation document (ISO 11609:2010) includes further labelling specifications, namely, expiry date, chemical form of fluoride, total fluoride concentration and a cautionary note regarding use in paediatric consumers. This last provision can be regarded as mandatory in terms of product safety and health benefits and therefore is a fulfilment of the objective of full consumer protection.

Unlike SANS requirements, ISO labelling regulations pertain to the tube alone. These standards typically refer to the tube as the primary package (i.e. the container in direct contact with the product and retained by the consumer following purchase). The primary package is thus paramount in communicating with the consumer. Notably, two further declarations, omitted from both the SANS and ISO frameworks, but frequently applied by manufacturers in the labelling of toothpastes are storage instructions and guidelines for use. Due to their importance with respect to consumer protection these variables were included in the quality assessments of labelling practices in the present study.

\section{AIMS AND OBJECTIVES}

The aim of the present study was to evaluate toothpaste packaging and labelling practices and the extent of the provision of consumer information. In order to achieve this aim, the objectives were: (i) to determine whether packaging and labelling practices on the sample aligned with SANS 1302:2008; (ii) to determine whether labelling practices on the sample complied with ISO 11609:2010 and (iii) to evaluate the quality of the information provided on toothpaste packaging.

\section{METHODOLOGY}

Fluoride toothpaste samples and sample size

A convenience sample of commercially available paediatric and adult fluoridated toothpastes, excluding herbal brands and those claiming to have toothwhitening properties, were purchased off the shelf of a Dis-Chem outlet located in metro Cape Town. The toothpastes sampled in this manner were used to formulate a 'gold standard' list (Table 1) which guided the collection of further samples from other retailers in the five provinces included in the study. A total of 300 fluoridated toothpastes $(n=300)$ were conveniently purchased across 10 sampling sites - from a major pharmaceutical outlet (Dis-Chem) and a food retailer (Pick ' $n$ Pay) located in each of five metropolitan municipalities (Cape Town, Durban, Port Elizabeth, Pretoria and Gauteng) of South Africa.

Each toothpaste sample was assessed for conformity with the packaging and marking regulations/variables stipulated in SANS 1302:2008 (ed. 1.1). ${ }^{4}$ The norms prescribed by this documentation were identified as variables 1 to 8 (Table 2).

As per ISO 11609:2010, labels were also studied for information on the chemical form of fluoride, the fluoride concentration, and the expiry date. ${ }^{5}$ If the fluoride concentration was expressed as a percent of volume $(\% \mathrm{w} / \mathrm{v})$ or weight $(\% \mathrm{w} / \mathrm{w})$, the value was converted to parts per million (ppm). Any additional information provided by manufacturers (e.g. descriptive name of the abrasive, agent, storage instructions, guidelines for use) and deemed essential in terms of consumer protection, were also recorded.

A number of variables, including toothpaste brand and name, nominal volume, manufacturer or distributor contact details, content description and the presence of the phrase 'fluoride toothpaste' were identical for the same toothpaste types irrespective of sampling site. Hence, to improve ease of interpretation, the data obtained was reported, wherever possible, in terms of the 'gold standard' list alone. This produced an effective total sample of 38 toothpastes. Toothpaste types were then codified from 1 to 38 (Table 1).

\section{RESULTS}

Locally manufactured and distributed products comprised $60 \%$ of the total initial sample $(n=300)$.

\section{Compliance with SANS 1302:2008 (Table 1 \& 2)}

All toothpastes $(n=300)$ complied with variables 1,4 and 6 - being contained within "leak- proof", collapsible tubes, presenting with a brand name/key identifier and bearing a manufacturer or distributor address respectively (Table 2). Likewise, all samples, excluding the toothpaste codified 10 were packaged in individual outer cartons (Variable 2). The packaging of toothpaste 10 was restricted to a tube alone and it may be assumed that this compromises the degree to which the toothpaste is protected against contamination and 
degradation under normal conditions of transportation, handling and storage. The absence of an outer carton for this product was taken into account in the calculation of box marking statistics.

According to SANS documentation it is only necessary for batch identification (Variable 3) to be displayed on the primary package. Nearly $85 \%$ of the toothpastes sampled (84.67\%; $n=300)$ presented with a tube batch identification, but $90,33 \%$ of boxes also had this information, although not required by SANS (Table 2, Variable 3).

Less than ten percent of toothpastes, codified 7,14,26 $(n=38)$ did not display the nominal volume (Variable 5). Quantity was still however declared in terms of weight in grams, with weights of $70 \mathrm{~g}, 125 \mathrm{~g}$ and $115 \mathrm{~g}$ reflected respectively.

The 'content description' regulation (Variable 7) implies through use of the term 'description' that a listing of all ingredients in conjunction with an explanation of the concentration and function of each ingredient be provided. Space limitations imposed by the outer carton and tube in conjunction with requirements that all information be presented in a visible and legible manner meant that for most toothpastes sampled, content 'description' was confined to a constituent list and frequently an indication of the active ingredient, the chemical form of fluoride and the concentration.

The presence of these elements (i.e. constituent list that included the abrasive agent as well as chemical form and concentration of fluoride) was regarded as conformance with this variable.

A majority, $89.47 \%$ of the sample $(n=38)$, provided an ingredients list (Table 2) on the outer carton. Non-observance was noted for toothpastes 7,10, 11 and 24 (Table 1). Samples 7 and 10 declared no information with respect to formulation and as a result gave no indication of the abrasive agent and fluoride content or chemical form, stating only that fluoride was present, while samples 11 and 24 did not stipulate fluoride concentration.

\begin{tabular}{|c|c|c|c|c|c|c|c|c|c|}
\hline \multirow[b]{3}{*}{$\begin{array}{l}\text { Toothpaste } \\
\text { Type Code }\end{array}$} & \multirow[b]{3}{*}{$\begin{array}{l}\text { Fluoridated Toothpaste } \\
\text { Samples }\end{array}$} & \multicolumn{8}{|c|}{ Sample Size $(n)=38$} \\
\hline & & $\begin{array}{c}\text { Batch } \\
\text { Identification } \\
\text { Tube Only }\end{array}$ & $\begin{array}{l}\text { Product } \\
\text { Name }\end{array}$ & $\begin{array}{l}\text { Nominal } \\
\text { Volume }\end{array}$ & $\begin{array}{l}\text { Manufacturer } \\
\text { Address }\end{array}$ & $\begin{array}{l}\text { Content } \\
\text { Description }\end{array}$ & $\begin{array}{l}\text { Product } \\
\text { Descriptor }\end{array}$ & $\begin{array}{l}\text { Number of } \\
\text { Regulations } \\
\text { Applied }\end{array}$ & $\begin{array}{c}\% \\
\text { Compliance } \\
\text { per Product }\end{array}$ \\
\hline & & & & & & & & & \\
\hline 1 & Aquafresh Milk Teeth 0-3yrs & 1 & 1 & 1 & 1 & 1 & 0 & 5 & 83.3 \\
\hline 2 & Aquafresh Little Teeth 4-6yrs & 1 & 1 & 1 & 1 & 1 & 0 & 5 & 83.3 \\
\hline 3 & Aquafresh Big Teeth >6yrs & 1 & 1 & 1 & 1 & 1 & 0 & 5 & 83.3 \\
\hline 4 & Colgate $0-2 y r s$ & 0 & 1 & 1 & 1 & 1 & 0 & 4 & 66.7 \\
\hline 5 & Colgate 2-5yrs & 1 & 1 & 1 & 1 & 1 & 0 & 5 & 83.3 \\
\hline 6 & Colgate $>5 y$ rs & 1 & 1 & 1 & 1 & 1 & 0 & 5 & 83.3 \\
\hline 7 & Dis-Chem Dentalmate Kids & 0 & 1 & 0 & 1 & 0 & 0 & 2 & 33.3 \\
\hline 8 & Elgydium Kids 2-6yrs & 1 & 1 & 1 & 1 & 1 & 0 & 5 & 83.3 \\
\hline 9 & Mentadent P Kids & 1 & 1 & 1 & 1 & 1 & 0 & 5 & 83.3 \\
\hline 10 & $\begin{array}{l}\text { Nature Fresh Junior } \\
\text { Toothpaste }\end{array}$ & 1 & 1 & 1 & 1 & 0 & 0 & 4 & 66.7 \\
\hline 11 & $\begin{array}{l}\text { Aquafresh all-in-one } \\
\text { Protection }\end{array}$ & 1 & 1 & 1 & 1 & 0 & 0 & 4 & 66.7 \\
\hline 12 & Aquafresh Extreme Clean & 1 & 1 & 1 & 1 & 1 & 0 & 5 & 83.3 \\
\hline 13 & Aquafresh Ultimate & 1 & 1 & 1 & 1 & 1 & 0 & 5 & 83.3 \\
\hline 14 & Close Up Deep Action & 1 & 1 & 0 & 1 & 1 & 0 & 4 & 66.7 \\
\hline 15 & Colgate Active Salt & 1 & 1 & 1 & 1 & 1 & 0 & 5 & 83.3 \\
\hline 16 & Colgate Gel & 1 & 1 & 1 & 1 & 1 & 0 & 5 & 83.3 \\
\hline 17 & Colgate MaxFresh & 0 & 1 & 1 & 1 & 1 & 0 & 4 & 66.7 \\
\hline 18 & $\begin{array}{l}\text { Colgate Maximum Cavity } \\
\text { Protection }\end{array}$ & 0 & 1 & 1 & 1 & 1 & 0 & 4 & 66.7 \\
\hline 19 & $\begin{array}{l}\text { Colgate Sensitive } \\
\text { Multiprotection }\end{array}$ & 1 & 1 & 1 & 1 & 1 & 0 & 5 & 83.3 \\
\hline 20 & Colgate Sensitive Pro-Relief & 1 & 1 & 1 & 1 & 1 & 0 & 5 & 83.3 \\
\hline 21 & Colgate Total 12 & 0 & 1 & 1 & 1 & 1 & 0 & 4 & 66.7 \\
\hline 22 & Colgate Pro-Gum Health & 0 & 1 & 1 & 1 & 1 & 0 & 4 & 66.7 \\
\hline 23 & Colgate Triple Action & 1 & 1 & 1 & 1 & 1 & 0 & 5 & 83.3 \\
\hline 24 & Dis-Chem Dentalmate & 1 & 1 & 1 & 1 & 0 & 0 & 4 & 66.7 \\
\hline 25 & Elgydium Sensitive & 1 & 1 & 1 & 1 & 1 & 0 & 5 & 83.3 \\
\hline 26 & Enamel Care & 1 & 1 & 0 & 1 & 1 & 0 & 4 & 66.7 \\
\hline 27 & GUM Caries Protect & 1 & 1 & 1 & 1 & 1 & 0 & 5 & 83.3 \\
\hline 28 & Mentadent P Gel Protection & 1 & 1 & 1 & 1 & 1 & 0 & 5 & 83.3 \\
\hline 29 & Mentadent P Micro Granules & 1 & 1 & 1 & 1 & 1 & 0 & 5 & 83.3 \\
\hline 30 & Mentadent P Protection & 1 & 1 & 1 & 1 & 1 & 0 & 5 & 83.3 \\
\hline 31 & Mentadent P Sensitive & 1 & 1 & 1 & 1 & 1 & 0 & 5 & 83.3 \\
\hline 32 & Oral B Pro-Expert & 1 & 1 & 1 & 1 & 1 & 0 & 5 & 83.3 \\
\hline 33 & Pepsodent & 1 & 1 & 1 & 1 & 1 & 0 & 5 & 83.3 \\
\hline 34 & Pepsodent Complete 8 & 1 & 1 & 1 & 1 & 1 & 0 & 5 & 83.3 \\
\hline 35 & Sensodyne Cool Gel & 1 & 1 & 1 & 1 & 1 & 0 & 5 & 83.3 \\
\hline 36 & Sensodyne Multi Care & 1 & 1 & 1 & 1 & 1 & 0 & 5 & 83.3 \\
\hline 37 & Sensodyne Rapid Action & 1 & 1 & 1 & 1 & 1 & 0 & 5 & 83.3 \\
\hline 38 & Sensodyne Repair \& Protect & 1 & 1 & 1 & 1 & 1 & 0 & 5 & 83.3 \\
\hline & $\begin{array}{l}\text { Total Compliant per } \\
\text { Regulation }\end{array}$ & 32 & 38 & 35 & 38 & 34 & 0 & & \\
\hline & $\begin{array}{l}\text { Proportion Compliant per } \\
\text { Regulation }\end{array}$ & 84.2 & 100 & 92.1 & 100 & 89.5 & 0 & & \\
\hline
\end{tabular}


As abrasives influence fluoride bioavailability and the rate of fluoride release, reflection of the abrasive agent in the list of ingredients is of paramount importance. ${ }^{6-9}$ Nearly all $(94.7 \%)$ of the toothpastes sampled $(n=38)$ displayed the abrasive name in listing of the constituents, although not designating it as the abrasive, so that recognition by the lay person may be difficult.

No toothpastes were found to conform to the Variable 8 product descriptor regulation in marking of the tube (i.e. presence of the phrase 'fluoride toothpaste' with a font size of $3 \mathrm{~mm}$ and in a colour distinct from the background). Eight $(n=38)$, however, did meet specifications in marking of the outer carton and included toothpastes 9, 15-19, 21 and 23, with the Colgate brand demonstrating greatest compliance.

\section{Compliance with SANS 1302:2008 (Table 1 \& 2)}

In contrast to the ISO 11609:2010 guidelines, ${ }^{5}$ a number of frank omissions are evident from theregulations of SANS 1302:2008 (edition 1.1). ${ }^{4}$ These omissions pertain to key information, namely, expiry date, chemical form of fluoride, total fluoride concentration, cautionary note regarding use in paediatric consumers, storage instructions and guidelines for use, the provision of which can be regarded as mandatory in terms of product safety and health benefits and therefore in the fulfilment of full consumer protection.

Take note that the two latter variables, storage instructions and guidelines for use are also absent from the ISO11609:2010 framework. Each sample was also evaluated in terms of these omitted variables (Table 3).

As is evident from Table 3, application of the 'additional' ISO labelling regulations (i.e. those not mentioned within SANS) in marking of the primary package is widely divergent with positive results ranging from $65.8 \%(n=38)$ for the cautionary note regarding use in paediatric consumers to $99 \%$ ( $n=300)$ for 'expiry date'. The 1\% failing to present an expiry date may be accounted for by the fact that ISO11609: 2010 guidelines only require that an expiry date be reflected if the product stability is less than 30 months. $^{5}$

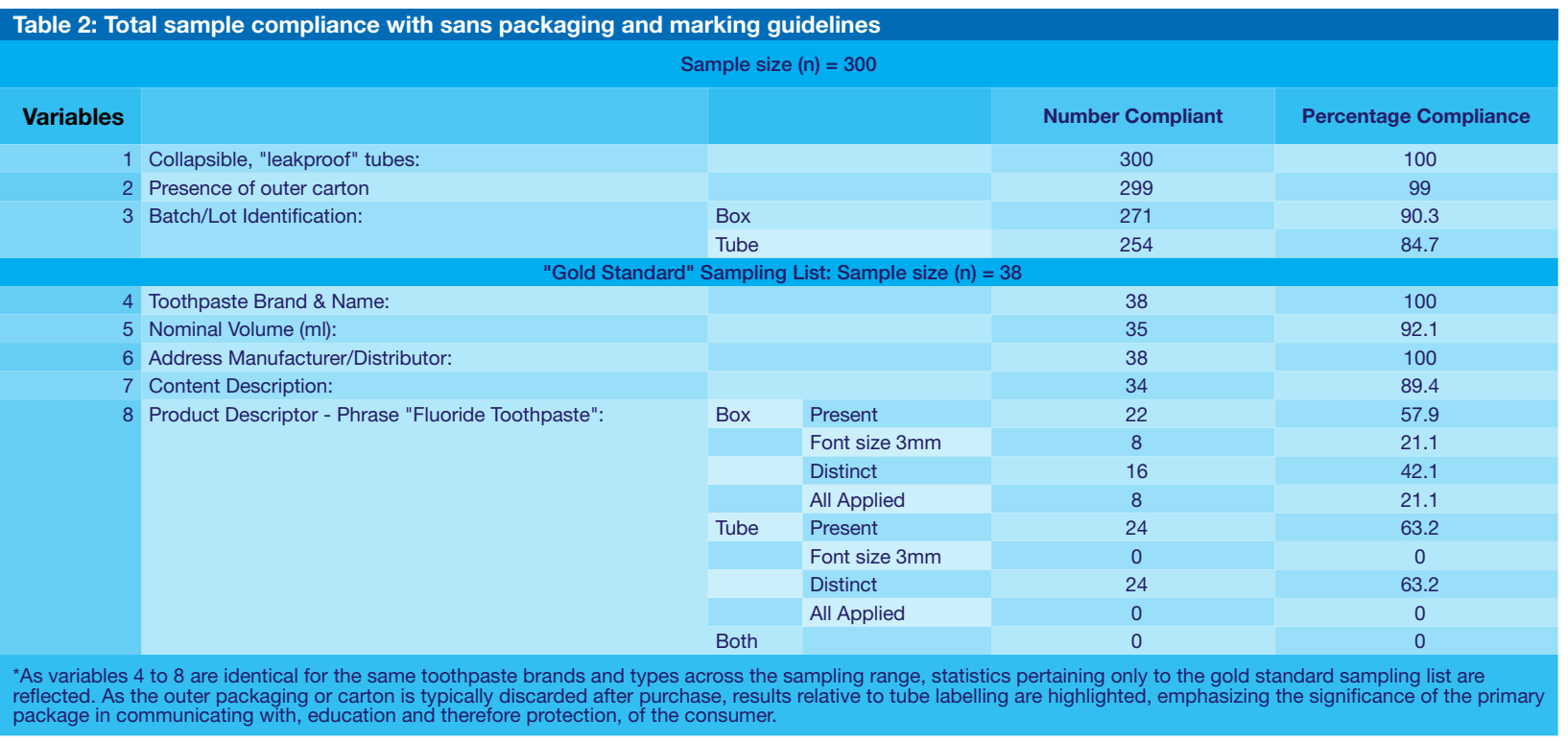

\begin{tabular}{|c|c|c|c|c|}
\hline \multicolumn{5}{|c|}{ Sample size $(n)=300$} \\
\hline Variables & & & Number Compliant & Percentage Compliance \\
\hline \multirow[t]{2}{*}{1} & \multirow[t]{2}{*}{ Stability/Expiry Date } & Box & 232 & 77.3 \\
\hline & & Tube & 297 & 99 \\
\hline \multicolumn{5}{|c|}{ "Gold Standard" Sampling List: Sample size $(n)=38$} \\
\hline 2 & Chemical Form of Fluoride & & 36 & 94.7 \\
\hline 3 & Total Fluoride Concentration & & 34 & 89.5 \\
\hline \multirow[t]{3}{*}{4} & \multirow[t]{3}{*}{ Safety Notice re. use in Paediatric Consumers } & Box & 35 & 92.1 \\
\hline & & Tube & 25 & 65.8 \\
\hline & & Both & 25 & 65.8 \\
\hline \multicolumn{5}{|c|}{ Additional information provided by manufacturers not covered in SANS 1302:2008 and ISO11609:2010 Frameworks. } \\
\hline \multirow[t]{3}{*}{5} & \multirow[t]{3}{*}{ Directions for use } & Box & 26 & 68.4 \\
\hline & & Tube & 18 & 47.4 \\
\hline & & Both & 13 & 34.2 \\
\hline \multirow[t]{3}{*}{6} & \multirow[t]{3}{*}{ Storage Instructions } & Box & 12 & 31.6 \\
\hline & & Tube & 10 & 26.3 \\
\hline & & Both & 10 & 26.3 \\
\hline
\end{tabular}


ISO labelling regulations pertain to the tube alone. Only $77.3 \%$ of toothpastes sampled displayed an expiry date in marking of the outer carton. Products lacking a stability declaration on the box included those codified $7,9,10,17,22,24$ as well as a number of samples of toothpaste 15 .

\section{DISCUSSION}

\section{Batch identification}

As demonstrated by the results in relation to batch identification (Variable 3) it was found, paradoxically, that fewer of the sampled toothpastes presented with a tube batch identification as opposed to the representation on the box, not actually a requirement. Non-compliance was primarily attributed to the illegibility of this information with numbers being smudged on the outer box or tube, or the imprint being superimposed onto the corrugated terminal tube seal.

\section{Product descriptor and content description}

In the interests of protecting the consumer against harm from the product and ensuring that intended health gains are attained, appropriate labelling that includes a readily visible product descriptor ('fluoride toothpaste') and quantity declaration of not only total, but also bioavailable fluoride content, is imperative.

Not all (total) fluoride incorporated into a toothpaste is available in soluble (bioavailable) form. A proportion is insoluble/inactive and does not contribute to caries inhibition or management. ${ }^{7,10}$ It is therefore obligatory that not only the total but also the active/bioavailable content be declared in the labelling of a product and that the bioavailable concentration exceed 1000ppm F in order for health benefits to be realized. ${ }^{3}$

In the present study, a minority of toothpastes (8), manufactured predominantly by Colgate were the only samples found to conform with the product descriptor regulation (Variable 8) in labelling of the outer carton. None, however, were found compliant in marking of the tube. With respect to content description (Variable 7 ), no declarations were made with respect to total soluble (potentially bioavailable) fluoride content.

Two probable explanations as to why bioavailable content is not declared in marking of the packaging could firstly be due to the fact that regulating authorities fail to recognise or adequately define differing fluoride species. This is supported by the fact that the SANS 1302:2008 (edition 1.1) provides guidance only with respect to an analysis of total fluoride content ${ }^{4}$ while the Medicines and Related Substances Act 101 of 1965 (R510) merely prescribes the maximum total fluoride concentration (1500ppm) that a toothpaste may contain. ${ }^{11}$ Secondly, fluoride bioavailability decreases over time in response to chemical incompatibility between toothpaste constituents $^{7}$ and the ambient conditions under which the toothpaste is stored and handled, ${ }^{6}$ rendering any declaration in terms of fluoride bioavailability of questionable integrity.
Anti-caries efficacy is reliant on soluble/bioavailable fluoride content. Recommended then is that this minimum total soluble/available fluoride concentration be declared on the label in conjunction with storage instructions, ${ }^{9,12}$ This would accord with the Federal Drug Administration's (FDA) anti-caries monograph which stipulates that manufacturers should formulate toothpastes in such a manner as to ensure maintenance of a minimum available fluoride content for the duration of a product's shelf-life, when stored and handled appropriately. It may, however, be anticipated that if this recommendation is to be met, additional analyses would need to be undertaken by manufactures, new formulations may need to be developed and labels would need to be updated, all procedures having significant financial implications.

Listing of the bioavailable fluoride content is a complex issue, although it is essential in terms of consumer protection. Regulating authorities would need to clearly define and acknowledge the presence of differing fluoride species. Manufacturers would have to hold a complete understanding of fluoridated toothpaste chemistry (i.e. the interaction of fluoride with other constituents of the toothpaste formulation and the impact of environmental conditions on these processes). These provisions would allow for the formulation of amendments to existing, or the generation of new, standards/norms and policies.

The majority of samples provided a content description or rather a listing of ingredients (Table 2) in marking of the outer carton.

Understandably, full content description (i.e. listing of constituents in conjunction with their function) is best practice in empowering consumers to make informed choices, but this may be impractical in terms of packaging. It is therefore advisable that in order to avoid misinterpretation that wording of the standard be amended to a 'complete listing of ingredients' that must include a statement with regards to the chemical form of fluoride, fluoride content declaration and designation of abrasive agent(s). Alternatively, to consider regulations in terms of product information sheets/inserts. Provision of such sheets would however markedly increase costs and the benefits in terms of consumer protection would have to be offset against affordability. Additionally, ISO 11609: 2010 standards require only that "a complete listing of ingredients according to the International Nomenclature of Cosmetic Ingredients (INCI)" be reflected. ${ }^{5}$ Toothpastes are indeed classified as cosmetic products within the South African context, and hence the use of this $1 \mathrm{NCl}$ phrasing may result from the fact that the SANS regulates packaging and marking subject to the 'Foodstuffs, Cosmetics and Disinfectants Act, 1972 (Act No. 54 of 1972; Regulation R1555). In the preface of this document, included within the list of definitions, 'describe' is said to include 'to advertise or label'13.

Extensive evidence, dating as far back as the first clinical trials undertaken to evaluate the anti-caries efficacy of fluoridated toothpastes, has demonstrated 
that abrasives influence fluoride bioavailability and the rate of fluoride release in response to chemical incompatibility between these components. ${ }^{6-9}$

Recent analytical studies have also repeatedly demonstrated that fluoride bioavailability declines markedly over time especially in toothpastes formulated with a calcium-containing abrasive as opposed to a silica-based abrasive or when subjected to excessive temperatures. $6,8,14$

In the interests of consumer protection and the realisation of intended health gains it is therefore imperative that consumers be educated with respect to abrasive agents in the toothpaste formulation, be alerted to the fact that anti-caries efficacy declines over time and markedly so with improper handling and storage. This highlights a need for identifying the abrasive agent(s) and legibly displaying the expiry date and storage instructions on the label.

The present study found that over three quarters of the toothpastes sampled displayed the abrasive in listing of the constituents together with an expiry date, while less than a third displayed storage instructions in marking of either the tube or outer carton.

\section{Expiry}

As fluoride bioavailability is reliant on product age and is a measure of efficacy it is fundamentally important that the stability of the toothpaste be specified through provision of an expiry date and it is for this reason that this variable, although not mentioned in the SANS parameters, receives special mention.

Declaration of an expiry date is preferable as opposed to a date of manufacture as the layperson is not necessarily aware that toothpastes have a shelf life and that the normal duration for which a product may be considered viable and safe for use is two years.

Additionally, conflicting information presents within the literature with respect to product stability.

Some researchers refer to a three-year shelf life ${ }^{6}$, while the ADA (American Dental Association) stipulates a two-year product stability. ${ }^{15}$

\section{South African Statutory Requirements}

Some marking regulations omitted from the SANS guidelines in contrast to ISO, may be accounted for by a clause which has been inserted into the edition 1.1 SANS 1302:2008 documentation, immediately below the heading, "4. Packing and Marking," which stipulates that all packing and marking practices must comply with current national legislation, namely the 'Foodstuffs, Cosmetics and Disinfectants Act, 1972 (Act No. 54 of 1972; Regulation R1555), the primary statute regulating the sale, manufacture, import and export of these substances. ${ }^{13}$ In recent years, especially since the ratification of the Consumer Protection Bill (Act No. 68 of 2008) in April 2010 and its coming into operation in March 2011, consumer rights and protection have garnered increasing attention. ${ }^{16}$ In association with this upsurge, amendments to the 'Foodstuffs, Cosmetics and Disinfectants Amendment Act, 2007 (Act No. 39 of 2007) and food labelling regulations (R146 of 2010) have been promulgated which focus, in particular, on revisions to labelling regulations, recognizing that adequate marking is a means of empowering the consumer to make informed choices and respecting his/her right to autonomy. ${ }^{17,18}$

The Cosmetics, Toiletries and Fragrance Association of South Africa (CTFA) states that in keeping with 'new' cosmetics labelling legislation, certain compulsory information, namely, brand name, product descriptor, directions for use, cautionary statements, ingredient listing and quantity declaration, be displayed in the marking of a product. ${ }^{19}$ Once again, no mention is made with respect to product stability/expiry, declaration of the active ingredient/s and concentration thereof, all of which are paramount to consumer safety.

As food, cosmetics and disinfectants are regulated under the same Act it is noteworthy that the 'new' Food labelling regulations, R146 (2010), do require that an expiry/use-by date be conspicuously displayed. ${ }^{18}$ Regulations pertaining to permissible fluoride content are also found in the Medicines and Related Substances Act 101 of 1965 (R510) which state that fluoride concentration shall not exceed a mass fraction of $0.15 \% .{ }^{11}$ This controls manufacture and formulation, but there is no mention made as to representation on the label. No reference is made within this Act with respect to the different fluoride ion species or chemical form of fluoride. ${ }^{11}$

According to the CTFA, South Africa ascribes to the European Regulations and Ingredient Annex to facilitate import and export. This provides an additional explanation as to why toothpaste labelling practices do not conform completely to SANS parameters and local legislation, but also partially adhere to ISO11609:2010 specifications. ${ }^{19}$

Appropriate packaging and marking is a complex process when one considers the multitude of Acts and associated amendments governing the sale, manufacture and advertisement of toothpastes, compounding the difficulties associated with comprehending the intricacies of legal discourse therein.

In summary, the SABS regulates packaging and marking as well as quantity declarations subject to the Foodstuffs, Cosmetics and Disinfectants Act, 1972 (Act No. 54 of 1972; Regulation R1555) ${ }^{13}$ and the Trade Metrology Act (Act No. 77 of 1973) ${ }^{20}$ respectively, while fluoride content is managed in accordance with the Medicines and Related Substances Act (Act 101 of 1965; Regulation R510). ${ }^{11}$

Additionally the National Consumer Commission over-sees improvements to standards of consumer information and the prohibition of unfair marketing practices, such as ambiguous and misleading labelling and advertising. ${ }^{21} \mathrm{~A}$ feasible recommendation, therefore, is that all regulations pertaining to 
manufacture, marking and packaging be clearly and comprehensibly documented in bullet format within SANS guidelines in a manner that provides no leeway for misinterpretation and as a result protects both the consumer against harm from the product as well as the manufacturer/distributor from legal liability.

Despite these statutory requirements, the South African cosmetics industry is self-regulated meaning that manufacturers and/or distributors are responsible for 'in-house' quality assurance. ${ }^{19}$ Periodic inspection by external authorities, such as SANS, must occur but the continued sale of products despite noncompliance, demonstrates an inability of authorities to impose restrictions.

Reasons cited for non-compliance with food labelling laws (R146) include a lack of awareness around labelling regulations or a misinterpretation of certain aspects of the provisions, purposeful disregard of legislative details in an attempt to remain competitive, high costs associated with compliance due to required laboratory testing and/or assistance provided by consultants and lawyers in legal interpretations, large expenses incurred in updating and changing labels and poor enforcement of regulations. ${ }^{22}$

As foodstuffs and cosmetics are regulated subject to Act 54 of 1972, all reasons discussed in terms of food labelling non-compliance are applicable to this research context as well. Lack of awareness and misinterpretation of legislation may stem from the fact that as a large proportion of toothpastes are imported, manufacturers lack familiarity with local laws (although it is anticipated that the major brands would have 'in-house' legal departments) and due to the multitude of acts governing marking procedures. Editing labels in an effort to achieve compliance is not only expensive but runs the risks of altering the key identifier by which the consumer recognises the product, reducing sales and competitive advantage, meaning that norms are ignored.

\section{CONCLUSION}

Partial compliance with marking requirements of SANS 1302:2008 (edition 1.1) was observed for all toothpastes sampled. That standard may, however, be regarded as weak as marking requirements with respect to information which is considered mandatory in terms of consumer protection, are omitted. On the other hand, a large number of manufacturers conformed to the ISO11609:2010 framework, which includes labelling regulations pertaining to this essential information and even went further in providing additional information, not regulated by either of the SANS or ISO marking criteria. Hence, the quality of consumer information provided on most toothpastes was evaluated as satisfactory.

In the interests of consumer protection, it is viable to recommend that at a minimum, SANS documentation be revised to align with ISO guidelines or alternatively to accept the complete adoption and implementation of the ISO framework within the South African context.
The ISO framework does includes labelling regulations (omitted from current SANS) pertaining to information which may be considered mandatory in terms of consumer protection and attainment of intended health gains. However, this standard may also be regarded as suboptimal due to the omission of norms relating to the designation of abrasive agent, the recognition and quantity declaration of differing fluo-ride species (total, soluble/bioavailable and insoluble), directions for use and appropriate storage instructions. Optimally, therefore, it is advisable that in addition to adoption of the ISO framework within the South African context, that national standards and policies be amended to embrace these variables as well.

In a consumer-centric environment in which labelling regulations are set to become more stringent and consumers more educated with respect to their rights, consumer protection (against harm and the realisation of intended health benefits) as well as legal accountability should provide sufficient motivation for manufacturers to become compliant with South African legislation, and with local and international standards.

\section{Ethical considerations}

The authors have no conflict of interest to declare. Ethical approval was granted by the Senate Research Committee of the University of the Western Cape.

(Project registration number 15/1/7)

This survey was undertaken during 2014/15 and it may be that the labels for certain of the toothpastes referred to herein have been updated.

\section{References}

1. Marinho VC, Higgind JP, Sheiham A, Logan, S. Fluoride toothpastes for preventing dental caries in children and adolescents. Cochrane Database Systematic Reviews [Internet]. 2003; [cited 2015 Oct 2]; (1) Art. No.:CD00227778 Available from: http:// onlinelibrary.wiley.com/doi/10.1002/14651858. CD002278/epdf/abstract.

2. Walsh T, Worthington HV, Glenny AM, Appelbe P, Marinho VCC, Shi X. Fluoride toothpastes concentrations for preventing dental caries in children and adolescents. Cochrane Database of Systemic Reviews [Internet]. 2010 Jan [cited 2014 Sep 7]; (1) Art. No.: CD007868:1-223. Available from: http://www2.cochrane.org/reviews/en/ab007868.html DOI:10.1002/14651858.CD007868.pub2.

3. van Loveren, C, Buijs MJ, van Palenstein Helderman WH. Total and free fluoride in toothpastes from some non-established market economy countries. Caries Res. 2005; 39: 224-30.

4. South African Bureau of Standards. Toothpaste. Pretoria: Standards South Africa; 2008. 21 p. Report No:1302:2008, edition 1.1; ISBN 978-0-626-21439-5.

5. European Commission for Standardisation. DentistryDentifrices-requirements, test methods and marking. Estonia: CEN; 2010. 19 p. Report No:EVS-EN ISO 11609:2010, ICS 97.170 .

6. Benzian, H, Holmgren $\mathrm{C}$, Buijs $\mathrm{M}$ et al. Total and free available fluoride in toothpastes in Brunei, Cambodia, Laos, the Netherlands and Suriname. Int Dent J. 2012; 62:213-21.

7. Cury JA, de Oliveira MJL, Martins CC, Tenuta LMA, Paiva SM. Available fluoride in toothpastes used by Brazilian children. Braz Dent J. 2010; 21: 396-400. 
8. Kikwilu EN, Frencken JE, Mulder J. Utilization of toothpaste and fluoride content in toothpaste manufactured in Tanzania. Acta Odontol Scand. 2008; 66:293-9.

9. Zero DT. Dentifrices, mouthwashes, and remineralization/caries arrestment strategies. BioMed Central [Internet]. $2006 \mathrm{Jul}$ [cited 2015 Jan 21]; 6(suppl 1):S9. Available from: http://www. biomedcentral.com/content/pdf/1472-6831-6-S1-S9.pdf DOl: 10.1186/1472-6831-6-S1-S9

10. Cury, JA. Use of the fluoride electrode to determine potentially available fluoride in different toothpaste formulations [Lecture notes]. Frankfurt:ORCA Workshop; 2015.

11. University of Pretoria and Southern African Legal Information Institute. Medicines and Related Substances Act 101 of 1965. Pretoria: SAFLII, (R510) [Internet]. 2014 Apr [cited 2015 Jun 24]. 170 p. Available from: http://www.saflii.austlii.edu.au/ za/legis/hist_reg/marsa10101965rangnr510723/marsa10101965rangnr510a2m2003796.pdf.

12. Sandier, M. The Regulation of Toothpastes. Third year paper: Harvard University [Internet]. 1997 [cited 2018 Jun 15]. Available from: http://nrs.harvard.edu/urn-3: HUL.InstRepos: 8846762

13. Department of Agriculture. Foodstuffs, Cosmetics and Disinfectants Act 54 of 1972 [Internet]. 1986 [cited 2015 Jun 11]. 15 p. Available from: http://www.nda.agric.za/vet we b/ Legislation/Other\%20acts/Act\%20-\%20Foodstuffs, \%20Cosmetics\%20and\%20Disinfectants\%20Act-54\%20 of\%201972.pdf.

14. De Oliveira NC, Rebelo MAB, Cury JA. Evaluation of the fluoride stability of dentifrices sold in Manaus, AM, Brazil. Pesqui Odontol Bras [Internet]. 2003 [cited 2015 Sep 1]; (3): 247-53. Available from: http://www.scielo.br/pdf/pob/v17n3/ a09v17n3.pdf.

15. American Dental Association [Internet]. Chicago:ADA Council on Scientific Affairs; 2005. Fluoride-Containing Dentifrices; 2005 Nov [cited 2015 Sep 1]; 25 p. Available from: http://www. ada.org/ /media/ADA/Science\%20and\%20Research/Files/ guide_fluoride_dentifrice.ashx.
16. South Africa. Consumer Protection Act, 2008. Act No. 68, 2008. Pretoria: Government Printing Works; 2009 Apr. 94 p. Report No.: 32186.

17. South Africa. Foodstuffs, Cosmetics and Disinfectants Amendment Act. Cape Town: Government Printing Works; 2008 Feb. 8p. Report No.: 30822

18. Department of Health. Regulations relating to the labelling and advertising of foodstuffs R146. Pretoria: Government Printing Works; 2010 Mar. 51 p. Report No.: 32975.

19. Cosmetics Toiletries and Fragrance Association South Africa. Advice from the CTFA for the consumer. Understanding product labeling and ingredient categories [Internet]. Northmead: CosmeticWeb; 2014 [updated 2014; cited 2015 Jun 24]. Available from: http:// www.cosmeticweb.co.za/ pebble. asp?relid=24786.

20. Department of Trade and Industry. Trade Meterology Act no. 77 of 1973. Balito: Enviroleg cc [Internet]; 1973 Jun [cited 2018 Jun 15]. 29 p. Available from: https://www.thedti.gov.za/ business_regulation/acts/metrology_act.pdf.

21. National Consumer Commission. Cape Town: Department of Trade and Industry. The DTI Agencies; 2018 [cited 2018 Jun 15]; [1 screen]. Available from: https://www.thedti.gov.za/ agencies/ncc.jsp.

22. Armer S. No More Excuses. It's time for industry players to get their cans in a line. Supermarket \& Retailer [Internet]. 2013 Jul [cited 2015 Jul 7]; 27-32. Available from: http:// www.supermarket.co.za/SR_Downloads/S\&R\%20July\%20 2013\%20Packaging.pdf.

\section{Do the CPD questionnaire on page 100}

The Continuous Professional Development (CPD) section provides for twenty general questions and five ethics questions. The section provides members with a valuable source of CPD points whilst also achieving the objective of CPD, to assure continuing education. The importance of continuing professional development should not be underestimated, it is a career-long obligation for practicing professionals.



Go to the SADA website www.sada.co.za.

2 Log into the 'member only' section with your unique SADA username and password.

3 Select the CPD navigation tab.

4 Select the questionnaire that you wish to complete.

5 Enter your multiple choice answers. Please note that you have two attempts to obtain at least $70 \%$

6 View and print your CPD certificate. 